\title{
The two-tier fecal occult blood test: Cost-effective screening
}

AJ RAE, IGM ClEATOR. The two-tier fecal occult blood test: Cost-effective screening. Can J Gastroenterol 1994;8(6):362-368. The two-tier test represents a strategy combining HO Sensa and Hemeselect fecal occult blood tests (FOBTs) with the aim of greater specificity and consequent economic advantages. If patients register a positive result on any HO Sensa guaiac test, they are once again tested by a hemoglobin-specific Hemeselect test. This concept was applied to a multicentre study involving persons 40 years or older. One component of the study enrolled 573 high risk patients while the second arm recruited an additional 1301 patients ( $52 \%$ asymptomatic/48\% symptomatic) stratified according to personal history and symptoms. The two-tier test produced fewer false positives than traditional tests in both groups evaluated in the study. In the high risk group, specificity ( $88.7 \%$ for two-tier versus $80.6 \%$ for Hemoccult and $69.5 \%$ for HO Sensa) was higher and false positive rates were lower ( $11.3 \%$ for two-tier versus $19.5 \%$ for Hemoccult and $30.5 \%$ for HO Sensa) for the two-tier test versus Hemoccult and HO Sensa FOBTs (95\% CI for all colorectal cancers [CRCs] and polyps greater than $1 \mathrm{~cm}, \alpha=0.05$ ). No significant differences in sensitivity were observed between tests in the same group. Also, in the high risk group, benefits of the two-tier test outweighed the costs. Due to the small number of cancers and polyps in the second arm of the study, presentation of data is meant to be descriptive and representative of trends in a 'normal' population. Nevertheless, specificity of the two-tier test was higher $(96.8 \%$ for two-tier versus $87.2 \%$ for Hemoccult and $69.5 \%$ for HO Sensa) and false positive rate lower $(3.2 \%$ for two-tier versus $12.8 \%$ for Hemoccult and $22.3 \%$ for HO Sensa) than either the Hemoccult or HO Sensa FOBT (95\% CI for all CRCs and polyps greater than $1 \mathrm{~cm}$ ). This initial study, focusing on the cost-benefit relationship of increased specificity, represents a new way of economically evaluating existing FOBTs.

Key Words: Colorectal cancer, Cost-benefit analysis, Fecal occult blood test, Twotier test

\section{Épreuve de dépistage en deux temps du sang occulte dans les} selles : méthode rentable

RÉSUMÉ : L'épreuve en deux temps est une stratégie diagnostique qui allie les avantages de deux tests de dépistage du sang occulte dans les selles, ceux du HO Sensa et du Hemeselect, dans le but d'obtenir un plus haut degré de spécificité

voir page suivante

GI Research Lab and GI Clinic, St Paul's Hospital, Vancouver, British Columbia

Correspondence: Mr Andrew Rae, Research Coordinator, GI Research Lab,

St Paul's Hospital, Vancouver, British Columbia V6Z 1Y6. Telephone (604) 682-2344

ext 2715, Fax (604) 631-5418

Received for publication February 17, 1994. Accepted June 8, 1994
C ANCER OF THE COLON AND RECtum is one of the most common internal malignancies in western nations for men and women combined. In Canada, the lifetime probability of developing colorectal cancer (CRC) and dying from it is approximately $6 \%$ and $3 \%$, respectively (1). Figures are increased in persons with familial polyposis syndromes, a history of CRC in a first degree relative or a personal history of neoplasms (2).

Due to the high prevalence of CRC, economic interest in the benefits of screening has grown. Mathematical models outlining the cost-benefit relationship of various fecal occult blood tests (FOBTs) have attempted to quantify money spent per life-year or quality-adjusted life-year gained. Today, FOBTs must not only prove effective but cost-effective. This has been raised by Mandel et al (3), who observed an "estimated benefit of a $33 \%$ reduction in mortality from colorectal cancer" after rehydrating Hemoccult tests (SmithKline Diagnostics, California) (yearly screen over age 40 ), yet caution that the economics of a fourfold increase in positives must be addressed.

Three of the most common FOBTs are the Hemoccult guaiac test, $\mathrm{HO}$ Sensa guaiac test (SmithKline Diagnostics) and Hemeselect hemaglutination test (SmithKline Diagnostics). Problems with these tests include low specificity (guaiac-based tests) and high screening costs (Hemeselect). The two-tier test, first described by 
et d'en tirer des avantages économiques. Si les patients obtiennent des résultats positifs au gaïac, ils subissent alors l'épreuve Hemeselect, spécifique à l'hémoglobine. Ce concept a été appliqué à une étude multicentrique qui portait sur des personnes de 40 ans et plus. Le premier des bras de l'étude comportait 573 patients à risque élevé, et le deuxième a recruté 1301 patients (53\% asymptomatiques et $48 \%$ symptomatiques) stratifiés en fonction de leurs antécédents personnels et de leurs symptômes. La double épreuve a donné lieu à un moins grand nombre de résultats faussement positifs que les épreuves classiques dans les deux groupes. Dans le groupe à risque élevé, la spécificité ( $88,7 \%$ pour la double épreuve, contre $80,6 \%$ pour Hemoccult et $69,5 \%$ pour HO Sensa) a été plus grande et les taux de faux positifs ont été moindres $(11,3 \%$ pour la double épreuve, contre $19,5 \%$ pour Hemoccult et 30,5\% pour HO Sensa) pour la double épreuve, en comparaison avec Hemoccult et HO Sensa (IC $95 \%$ pour tous les cancers rectocoliques et les polypes de plus de $1 \mathrm{~cm}, \alpha=0,05)$. Aucune différence significative sur le plan de la sensibilité n'a été notée entre les tests au sein d'un même groupe. Également, dans le groupe à risque élevé, les coûts de la double épreuve ont été compensés par ses avantages. Vu le nombre restreint de cancers et de polypes présents dans le deuxième bras de l'étude, la présentation des données se veut descriptive et représentative des tendances dans la population «normale». Néanmoins, la spécificité de la double épreuve a été plus grande $(96,8 \%$ pour cette dernière, contre $87,2 \%$ pour Hemoccult et $69,5 \%$ pour HO Sensa) et les taux de faux positifs ont été moindres (3,2\% pour la double épreuve, contre $12,8 \%$ pour Hemoccult et 22,3\% pour HO Sensa) qu'avec les tests Hemoccult ou $\mathrm{HO}$ Sensa (IC $95 \%$ pour tous les cancers et les polypes de plus de $1 \mathrm{~cm}$ ). Cette étude initiale, qui se penchait sur les avantages économiques d'un degré accru de spécificité, représente une nouvelle façon d'évaluer rentablement les tests de dépistage du sang dans les selles.

Cleator (4) in 1990, represents an attempt to increase specificity in screening (while maintaining sensitivity) and thus reduce costs associated with false positives. Clearly, these two aims must be addressed by any FOBT if widespread acceptance is to be won in our costconscious society.

\section{SUBJECTS AND METHODS}

Multiple sites (St Paul's Hospital, Vancouver, British Columbia, George Washington University, Washington DC, and several primary care sites in California, Florida and Pennsylvania) were part of this multicentre study involving gastroenterologists and primary care physicians. In the first arm of the study a high risk group $(n=573)$ comprised patients ( $59 \%$ male, $41 \%$ female) 40 years of age or older, mean age 64.9 (range 40 to 90). In each of these cases, patients were referred to gastroenterologists for large bowel work-up for one or more of the following reasons: previous positive stool tests; symptomatic case; personal history of CRC, polyps or inflammatory bowel disease; family history of colorectal neo- plasia or polyps; and iron deficiency anemia. Only patients who completed all FOBTs were included in this report.

All patients, regardless of the FOBT results, underwent a complete large bowel work-up. All invasive procedures were performed after the testing and results were correlated to FOBT results. Of the 1301 patients (59\% male, $41 \%$ female) involved in the second arm of the study, all were 40 years of age or older, mean age 63.1 (range 40 to 92). Fifty-two per cent were asymptomatic without a history of gastrointestinal disorders while $48 \%$ displayed either minor symptoms or expressed some personal or family history of gastrointestinal disorders.

Further description of these 1301 patients is as follows: 678 asymptomatics with no personal history of gastrointestinal disease or family history of CRC or polyps; 234 patients with either a personal history of one or more of the following: hemorrhoids, anal fissures, upper gastrointestinal disease, diverticular disease, miscellaneous lower gastrointestinal disease, or nonspecific symptoms (with respect to CRC) such as diarrhea, nausea, bloating, fatigue or incontinence; and 389 patients exhibiting personal history of nongastrointestinal cancer, or specific symptoms (with respect to colon cancer) such as visible blood in stool, melena, weight loss, abdominal pain, anemia, rectal pain, change in stool calibre or change in bowel habits, or asymptomatic patients with family history of CRC or polyps, or personal history of ulcerative colitis, Crohn's disease or other inflammatory bowel disease, or personal history of CRC, adenomas or hyperplastic polyps.

In this second arm of the study, patients were visiting a physician for routine physical examination or for surveillance follow-up after personal history of CRC, polyps or inflammatory bowel disease. Patients may have had a personal or family history of colorectal neoplasia. Only patients who performed all the FOBTs for three days were included in this report. It is important to note that not all patients in this arm of the study can be considered average risk patients. In this part of the study, patients who tested positive in any of the FOBTs were asked to undergo diagnostic follow-up. A complete follow-up consisted of full colonoscopy, although a combination of flexible sigmoidoscopy and double air contrast barium enema was also considered adequate follow-up.

FOBTs studied were the Hemoccult, HO Sensa, Hemeselect and two-tier tests. The Hemoccult test is guaiacbased and detects oxidizing agents in fecal samples. It is simple and economical but may register false positives and false negatives when meat and vitamin C, respectively, are part of the subject's diet. HO Sensa is a more sensitive guaiac-based test than the Hemoccult test. It is simple to perform but less economical than the Hemoccult test. Hemeselect's advantages include fewer false negatives and positives due to the fact that it detects human hemoglobin in fecal matter. Unfortunately it is much more costly - approximately seven times more - than Hemoccult or $\mathrm{HO}$ Sensa and requires laboratory analysis. The two-tier test, as previously observed, confirms positives 
TABLE 1

High risk group

\begin{tabular}{|c|c|c|c|c|c|}
\hline \multirow[b]{2}{*}{ Clinical classification (findings) } & \multirow[b]{2}{*}{$\begin{array}{l}\text { Number } \\
\text { of cases }\end{array}$} & \multicolumn{4}{|c|}{ Positive cases with different FOBTs } \\
\hline & & $\begin{array}{l}\text { Hem- } \\
\text { occult }\end{array}$ & $\begin{array}{l}\text { HO } \\
\text { Sensa }\end{array}$ & $\begin{array}{l}\text { Heme- } \\
\text { select }\end{array}$ & $\begin{array}{c}\text { Two-tier } \\
\text { test }\end{array}$ \\
\hline Colorectal cancers & 23 & 19 & 20 & 19 & 19 \\
\hline Dukes A \& B & 10 & 7 & 8 & 7 & 7 \\
\hline Other CRCs & 13 & 12 & 12 & 12 & 12 \\
\hline Adenomas, polyps & 129 & 43 & 61 & 37 & 29 \\
\hline$>2.0 \mathrm{~cm}$ & 13 & 10 & 10 & 7 & 6 \\
\hline 1.1 to $2 \mathrm{~cm}$ & 22 & 12 & 14 & 15 & 11 \\
\hline 0.5 to $1 \mathrm{~cm}$ & 42 & 12 & 22 & 10 & 9 \\
\hline$<0.5 \mathrm{~cm}$ & 52 & 9 & 15 & 5 & 3 \\
\hline Nonadenomatous polyps & 46 & 8 & 12 & 3 & 3 \\
\hline Miscellaneous upper GI problems & 13 & 6 & 6 & 2 & 2 \\
\hline Miscellaneous lower GI problems & 30 & 3 & 5 & 4 & 3 \\
\hline Ulcerative colitis & 3 & 3 & 2 & 3 & 2 \\
\hline Crohn's disease, other IBDs & 8 & 5 & 5 & 5 & 3 \\
\hline Diverticular disease & 115 & 22 & 34 & 14 & 11 \\
\hline Hemorrhoids/fissures & 47 & 11 & 19 & 9 & 7 \\
\hline Anemia of unknown origin & 19 & 5 & 5 & 5 & 4 \\
\hline Normals: confirmed, asymptomatic & 45 & 5 & 6 & 7 & 5 \\
\hline Normals: confirmed with GI history & 68 & 7 & 18 & 3 & 3 \\
\hline $\begin{array}{l}\text { Normals: confirmed with } \\
\text { symptoms }\end{array}$ & 27 & 4 & 8 & 4 & 3 \\
\hline Total & 573 & 141 & 201 & 115 & 94 \\
\hline
\end{tabular}

CRC Colorectal cancer; FOBT Fecal occult blood test: GI Gastrointestinal; IBD Inflammatory bowel disease

from HO Sensa tests with the Hemeselect test. This affords a high specificity without the significant cost of performing a Hemeselect test on every subject.

Ethical approval was obtained from respective study sites. Study participants were given sample kits containing three envelopes for FOBTs. Each envelope consisted of one Hemoccult test card, one HO Sensa test card, one Hemeselect test card, a collection saddle, wooden applicator sticks, patient instructions and a return envelope. Fecal samples were then collected and applied to all sample cards by individuals over three consecutive bowel movements. Persons were given additional instructions by a nurse or physician's assistant. Individuals were asked to abide by a restricted diet during and three days before testing. This included no consumption of red meat, fruits and vegetables (including turnips, melons, radishes, horseradish, broccoli and cauliflower) and was done to avoid inaccurate testing as a result of red meat, high peroxidase vegetables, nonsteroidal anti-inflammatory drugs and vitamin $\mathrm{C}$ (more than $250 \mathrm{mg} /$ day). Females were also asked not to sample stool during menstruation and for the following three days. All cards were then analyzed by technicians who were blinded to physician's observations and, in the case of the two-tier test, results of $\mathrm{HO}$ Sensa when analyzing Hemeselect tests. Rehydration did not take place.

A two-tier approach was conducted when any one of the HO Sensa guaiac tests registered a positive result. At that point, Hemeselect results from the same patient were examined. The relationship of these two tests was then assessed for sensitivity, specificity, predictive value and estimated costs for screening where possible.

As earlier mentioned, all patients in plete bowel work-up following FOBT administration, while all patients registering positive on FOBTs in the second arm of the study were similarly examined.

Clinical findings were recorded for numbers (and stage) of CRCs, adenomatous and nonadenomatous polyps, nonthe high risk group underwent a com-
CRC bleeding, gastrointestinal disorders and asymptomatic cases. In the second arm of the study, findings were expressed in terms of an 'all risk' group $(\mathrm{n}=1301)$ and asymptomatic subgroup $(n=678)$ for patients recorded as asymptomatic or possessing no previous history of gastrointestinal disease or family history of CRC.

Certain assumptions were made in the cost-benefit analysis of the two-tier test within a Canadian medical system. Cost of colonoscopy was set at $\$ 300$, cost to repair perforations due to colonoscopy was estimated to be $\$ 6,000$ (including surgery and seven- to 10-day hospital stay), and the commonly accepted perforation rate of $1 / 1000$ was assumed.

Statistics: Confidence intervals of $95 \%$ were set $(\alpha=0.05)$ when comparing sensitivities, specificities and predictive values, as well as false positive and false negative rates, of various FOBTs. Confidence limits for proportion were based on $\mathrm{F}$ distribution and binomial distribution.

\section{RESULTS}

As previously mentioned, the data stem from studies that involved both gastroenterologists and primary care physicians at multiple sites. Stratification of the data based on risk codes was performed. The first component ( $\mathrm{n}=573$ ) of the study comprised a high risk group, and the second component ( $\mathrm{n}=1301)$ was made up of asymptomatic and symptomatic subgroups reflecting the make-up of primary care practices involved in the study. An asymptomatic subgroup $(n=678)$ from the second component of the investigation was studied in an identical fashion to the larger arms of the study to estimate costs associated with a normal screening population.

In the high risk group $(\mathrm{n}=573) 23$ patients were determined to have CRC upon complete large bowel work-up (Table 1). Hemoccult, Hemeselect and the two-tier tests were positive in 19 of these cases, while the number of positives for HO Sensa was 20. For adenomas and polyps greater than $1.0 \mathrm{~cm}$, Hemoccult picked up 22, HOSensa 24, Hemeselect 22 and the two-tier test 17. 
A value of greater than $1.0 \mathrm{~cm}$ for polyps was selected for statistical comparison of tests (the rationale for this designation will be addressed in the 'Discussion'). The Hemoccult, HO Sensa, Hemeselect and two-tier FOBTs registered 79, 120, 59 and 46 false positives, respectively, for this arm of the study. Many of these false positives were associated with hemorrhoids or fissures, diverticular disease, Crohn's disease, inflammatory bowel disease, ulcerative colitis, nonadenomatous polyps, and miscellaneous upper and lower gastrointestinal problems. The two-tier test produced fewer false positives than traditional tests in both groups evaluated in the study. In the high risk group, specificity $(88.7 \%$ for two-tier versus $80.6 \%$ for Hemoccult and $69.5 \%$ for HO Sensa) was significantly higher and false positive rates were significantly lower $(11.3 \%$ for two-tier versus $19.5 \%$ for Hemoccult and $30.5 \%$ for HO Sensa) for the twotier test versus Hemoccult and $\mathrm{HO}$ Sensa FOBTs (95\% CI for all CRCs and polyps greater than $1 \mathrm{~cm}, \alpha=0.05$ ). No statistically significant differences in sensitivity were observed among tests in the same group (Hemoccult $70.7 \%$, HO Sensa $75.8 \%$, two-tier $62 \%$; $\alpha=0.5$ ).

In the high risk group, the benefits of the two-tier test markedly outweighed the costs, even when one less detected cancer (two-tier versus $\mathrm{HO}$ Sensa) was figured into calculations. In the high risk group the cost per detected cancer was $\$ 2,361, \$ 3,176$ and $\$ 2,485$ for Hemoccult, HO Sensa and Hemeselect tests, respectively (Table 2). This is in contrast to the $\$ 1,842$ for the two-tier FOBT. Even when determining cost per detected cancer as well as adenomas and polyps greater than $1 \mathrm{~cm}$, the two-tier test remains the most cost-effective at $\$ 972$.

Due to the small number of cancers and polyps in the second arm of the study, presentation of data is meant to be descriptive and representative of trends in a 'normal' population. Nevertheless, specificity of the two-tier test was significantly higher $(96.8 \%$ for two-tier versus $87.2 \%$ for Hemoccult and $69.5 \%$ for HO Sensa) and false

TABLE 2

First arm of the study: High risk group $(n=573)$

\begin{tabular}{lrrrr} 
& Hemoccult & HO Sensa & Hemeselect & Two-tier \\
\hline Cost of tests & $\$ 1,719$ & $\$ 2,006$ & $\$ 12,033$ & $\$ 6,227$ \\
Colonoscopy for D, H, F & $\$ 9,900$ & $\$ 15,900$ & $\$ 6,900$ & $\$ 5,400$ \\
Colonoscopy complications & $\$ 846$ & $\$ 1,206$ & $\$ 690$ & $\$ 564$ \\
$\quad \begin{array}{l}\quad \$ 6,000 \text { for perforation) } \\
\text { Colonoscopy for all other positives }\end{array}$ & $\$ 32,400$ & $\$ 44,400$ & $\$ 27,600$ & $\$ 22,800$ \\
Totals & $\$ 44,865$ & $\$ 63,512$ & $\$ 47,223$ & $\$ 34,991$ \\
Cost per cancer detected & $\$ 2,361$ & $\$ 3,176$ & $\$ 2,485$ & $\$ 1,842$ \\
$\begin{array}{l}\text { Cost per cancer and adenomas/ } \\
\quad \text { polyps }>1 \text { cm detected }\end{array}$ & $\$ 1,094$ & $\$ 1,444$ & $\$ 1,152$ & $\$ 972$ \\
\hline
\end{tabular}

All costs are expressed in Canadian dollars. D Diverticulitis; F Fissures; H Hemorrhoids

\section{TABLE 3}

Second arm of the study: Asymptomatic and symptomatic subgroups combined ( $n=1077$ when incomplete data excluded)

\begin{tabular}{lrrrr}
\hline & Hemoccult & HO Sensa & Hemeselect & Two-tier \\
\hline Cost of tests & $\$ 3,231$ & $\$ 3,770$ & $\$ 22,617$ & $\$ 9,104$ \\
Colonoscopy for D, H, F & $\$ 23,100$ & $\$ 37,200$ & $\$ 9,000$ & $\$ 5,700$ \\
$\begin{array}{l}\text { Colonoscopy complications } \\
\quad(\$ 6,000 \text { for perforation) }\end{array}$ & $\$ 924$ & $\$ 1,524$ & $\$ 378$ & $\$ 246$ \\
Colonoscopy for all other positives & $\$ 23,100$ & $\$ 39,000$ & $\$ 9,900$ & $\$ 6,600$ \\
Totals & $\$ 50,355$ & $\$ 81,494$ & $\$ 41,895$ & $\$ 21,650$ \\
Cost per cancer detected & $\$ 25,178$ & $\$ 27,165$ & $\$ 20,948$ & $\$ 10,825$ \\
\hline
\end{tabular}

All costs are expressed in Canadian dollars. D Diverticulitis; F Fissures; H Hemorrhoids. Hemoccult $=\$ 3 / 3$ tests: HO Sensa=\$3.50/3 tests: Hemeselect=\$21/3 tests; Two-tier $=\$ 3.50 / 3$ HO Sensatests $(+\$ 21$ for Hemeselect tests in the case of positive HO Sensa); Colonoscopy $=\$ 300$; Perforation $=\$ 6,000$; Rate of perforation $=1 / 1000$

positive rate significantly lower $(3.2 \%$ for two-tier versus $12.8 \%$ for Hemoccult and $22.3 \%$ for HO Sensa) than either the Hemoccult or HO Sensa FOBT $(95 \% \mathrm{Cl}$ for all CRCs and polyps greater than $1 \mathrm{~cm}$ ). Statistical differences in sensitivity were not observed (Hemoccult 66.7\%, two-tier 66.7\%, $\alpha=0.05$ ).

In the second arm $(n=1301)$, benefits outweighed costs, and are perhaps more reflective of savings associated with screening a normal population (though the limited number of cancers detected restricts what can be said of the data). Because HO Sensa detected three cancers versus two in all other FOBTs, total cost of detection is divided by three (for HO Sensa). As a result cost per detected cancer is $\$ 25,178$ for Hemoccult, $\$ 27,165$ for HO Sensa, $\$ 20,948$ for Hemeselect and $\$ 10,825$ for two-tier test (incomplete findings were not calculated into cost per detected cancer) (Table 3).

In the second arm $(n=1301)$, false positive rates were of great interest, particularly because they were more reflective of a somewhat 'normal' population (Tables 4,5). Diverticular disease, hemorrhoids and fissures, miscellaneous gastrointestinal problems, anemia and nonadenomatous polyps resulted in non-CRC bleeding in 108 Hemoccult, 173 HO Sensa, 44 Hemeselect and 28 two-tier tests. Additionally, confirmed or assumed confirmed asymptomatic false positives added 32,61 , nine and four additional false positives for Hemoccult, HO Sensa, Hemeselect and the two-tier test, respectively.

Additionally, in this arm of the study, three cancers were detected by HO Sensa and two by all other tests. Sensitivity (for all CRCs and polyps greater than $1 \mathrm{~cm}$ ) figures did not differ significantly (at 95\% Cl, $\alpha=0.05$ ). In the asymptomatic subgroup $(n=678)$ from the second component of the study one CRC was detected by all FOBTs except Hemoccult. What the present authors were most interested 
TABLE 4

\section{All risk codes $(0$ to 7$)$}

\begin{tabular}{|c|c|c|c|c|c|}
\hline \multirow[b]{2}{*}{ Clinical classification (findings) } & \multirow[b]{2}{*}{$\begin{array}{l}\text { Number } \\
\text { of cases }\end{array}$} & \multicolumn{4}{|c|}{ Positive cases with different FOBTs } \\
\hline & & $\begin{array}{l}\text { Hem- } \\
\text { occult }\end{array}$ & $\begin{array}{l}\text { HO } \\
\text { Sensa }\end{array}$ & $\begin{array}{l}\text { Heme- } \\
\text { select }\end{array}$ & $\begin{array}{c}\text { Two-fier } \\
\text { test }\end{array}$ \\
\hline Colorectal cancers & 3 & 2 & 3 & 2 & 2 \\
\hline Dukes A \& B & 1 & 0 & 1 & 1 & 1 \\
\hline Other CRCs & 2 & 2 & 2 & 1 & 1 \\
\hline Adenomas, polyps & 29 & 12 & 17 & 8 & 7 \\
\hline$>2.0 \mathrm{~cm}$ & 2 & 1 & 2 & 2 & 2 \\
\hline 1.1 to $2 \mathrm{~cm}$ & 4 & 4 & 3 & 2 & 1 \\
\hline 0.5 to $1 \mathrm{~cm}$ & 7 & 4 & 4 & 3 & 3 \\
\hline$<0.5 \mathrm{~cm}$ & 16 & 3 & 8 & 1 & 1 \\
\hline Nonadenomatous polyps & 14 & 3 & 6 & 1 & 1 \\
\hline Unknown histology polyps & 10 & 7 & 8 & 2 & 2 \\
\hline Miscellaneous upper GI problems & 52 & 7 & 16 & 3 & 1 \\
\hline Miscellaneous lower GI problems & 34 & 9 & 12 & 4 & 2 \\
\hline Ulcerative colitis & 5 & 3 & 2 & 1 & 1 \\
\hline Crohn's disease, other IBDs & 6 & 2 & 3 & 3 & 2 \\
\hline Diverticular disease & 210 & 46 & 67 & 18 & 11 \\
\hline Hemorrhoids/fissures & 156 & 31 & 57 & 12 & 8 \\
\hline Anemia of unknown origin & 5 & 0 & 2 & 0 & 0 \\
\hline Normals: confirmed, asymptomatic & 55 & 6 & 14 & 1 & 0 \\
\hline Normals: confirmed with GI history & 35 & 4 & 6 & 2 & 2 \\
\hline Normals: confirmed with symptoms & 26 & 2 & 3 & 1 & 0 \\
\hline $\begin{array}{l}\text { Normals: presumed, } \\
\text { asymptomatic }\end{array}$ & 437 & 20 & 38 & 5 & 2 \\
\hline $\begin{array}{l}\text { No report on findings, incomplete } \\
\text { data, presumed normals }\end{array}$ & 224 & 19 & 42 & 7 & 5 \\
\hline Total & 1301 & 173 & 296 & 70 & 46 \\
\hline
\end{tabular}

CRC Colorectal cancer; FOBT Fecal occult blood test; GI Gastrointestinal; IBD Inflammatory bowe disease

TABLE 5

Risk code $0^{*}$

\begin{tabular}{|c|c|c|c|c|c|}
\hline \multirow[b]{2}{*}{ Clinical classification (findings) } & \multirow[b]{2}{*}{$\begin{array}{l}\text { Number } \\
\text { of cases }\end{array}$} & \multicolumn{4}{|c|}{ Positive cases with different FOBTs } \\
\hline & & $\begin{array}{l}\text { Hem- } \\
\text { occult }\end{array}$ & $\begin{array}{l}\text { HO } \\
\text { Sensa }\end{array}$ & $\begin{array}{l}\text { Heme- } \\
\text { select }\end{array}$ & $\begin{array}{c}\text { Two-tier } \\
\text { test }\end{array}$ \\
\hline Colorectal cancers & 1 & 0 & 1 & 1 & 1 \\
\hline Dukes A \& B & 1 & 0 & 1 & 1 & 1 \\
\hline Adenomas, polyps & 7 & 2 & 3 & 2 & 2 \\
\hline 0.5 to $1 \mathrm{~cm}$ & 3 & 2 & 2 & 2 & 2 \\
\hline$<0.5 \mathrm{~cm}$ or unknown size & 4 & 0 & 1 & 0 & 0 \\
\hline Nonadenomatous polyps & 5 & 0 & 2 & 0 & 0 \\
\hline Unknown histology polyps & 2 & 1 & 1 & 0 & 0 \\
\hline Miscellaneous upper GI problems & 1 & 0 & 0 & 0 & 0 \\
\hline Miscellaneous lower $\mathrm{Gl}$ problems & 1 & 0 & 0 & 0 & 0 \\
\hline Crohn's disease, other IBDs & 1 & 0 & 0 & 0 & 0 \\
\hline Diverticular disease & 50 & 9 & 13 & 4 & 1 \\
\hline Hemorrhoids/fissures & 43 & 7 & 8 & 1 & 0 \\
\hline Normals: confirmed, asymptomatic & 50 & 6 & 13 & 1 & 0 \\
\hline $\begin{array}{l}\text { Normals: presumed, } \\
\text { asymptomatic }\end{array}$ & 417 & 20 & 36 & 5 & 2 \\
\hline $\begin{array}{l}\text { No report on findings, incomplete } \\
\text { data, presumed normals }\end{array}$ & 100 & 7 & 15 & 2 & 2 \\
\hline Total & 678 & 52 & 92 & 16 & 8 \\
\hline
\end{tabular}

-Asymptomatics, no personal history of gastrointestinal (GI) disease, no family history of colorectal cancer (CRC) or polyps. FOBT Fecal occult blood test; IBD Inflammatory bowel disease in, however, were the marked differences in false positives. The number of false positives that were presumably related to diverticular disease, hemorrhoids and fissures, and nonadenomatous polyps varied substantially between tests. Hemoccult registered 17 false positives, HO Sensa 24, Hemeselect five and the two-tier test one. In addition to these results, false positives recorded in nonbleeding subjects made up an additional 26,49 , six and two cases for Hemoccult, HO Sensa, Hemeselect and two-tier test, respectively.

\section{DISCUSSION}

As previously noted, the costs and resultant benefits of CRC screening have been widely discussed in recent years. Eddy $(5,6)$ has initiated much of this study, proposing his own mathematical model. This research has dealt with cost-effectiveness of screening both high risk patients and an average risk population. Other contributors have included Walker and Whynes (7) who assessed 13 screening strategies and made their own economic evaluations of each filter type. They accurately note that though "cost-effective screening protocols following the administration of one or other of the FOB tests" have been researched, "little attention has thus far been paid to the selection of the most appropriate filter from among the range available" (7). Trehu and Cooper (8) have also contributed to our knowledge, providing a very recent estimate of $\$ 15,233$ per case of colon cancer diagnosed through mass screening in the United States. Additionally, The Office of Technology Assessment (OTA) in the United States has assumed a lifetime price tag of $\$ 1.5$ billion to screen those 2.1 million individuals who are 65 years and older, resulting in 45,000 years being added to these person's lives (9). In this assessment, costs per year of life added come very close to screening procedures such as mammography (9).

In summary, Eddy and the OTA have done the most comprehensive work in this field. Byers and Gorsky (10) recognize this in their article which reviews the contributions of both these groups. By their estimates the range of net cost 
per day of life gained is between US\$57 (Eddy) and US\$118 (OTA).

What we feel is missing in these assessments is a closer look at the economics of each FOBT, as Walker and Whynes suggest. It is at this stage that we present the reduction in false positives associated with the two-tier test, which carries with it an economic advantage over individual Hemoccult, HO Sensa and Hemeselect tests. We argue that such economic benefits are found because of the innate specificity of HO Sensa and Hemeselect used in combination. Goosenberg (11) hints at this in a recent article, concluding that "an ideal test should combine the specificity of an immunologic test with the sensitivity of a guaiac test".

Because the two-tier approach, upon administration followed by complete large bowel work-up, affords detection of a similar number of CRCs while reducing the number of false positives (Table 1), we note that it thus possesses a relationship in which benefits outweigh costs.

In our high risk group the cost per detected cancer was $\$ 2,361, \$ 3,176$ and $\$ 2,485$ for Hemoccult, HO Sensa, and Hemeselect tests, respectively (Table 2 ), which is in contrast to the $\$ 1,842$ for the two-tier FOBT. Even when determining cost per detected cancer as well as adenomas and polyps greater than $1 \mathrm{~cm}$, the two-tier test remains the most cost-effective at $\$ 972$.

In the second arm $(n=1301)$, benefits outweigh costs and are perhaps more reflective of savings associated with screening a normal population (though the limited number of cancers detected restricts what can be said of the data). Due to the fact that $\mathrm{HO}$ Sensa detected three cancers versus two in all other FOBTs, total cost of detection is divided by three. As a result cost per detected cancer is $\$ 25,178$ for Hemoccult, $\$ 27,165$ for HO Sensa, $\$ 20,948$ for Hemeselect and $\$ 10,825$ for two-tier test (incomplete findings were not calculated into cost per detected cancer) (Table 3). Clearly, an apparent 'missed' cancer raises questions regarding the two-tier test, which we answer later.

Examination of the asymptomatic

TABLE 6

Second arm of the study: Asymptomatic subgroup ( $n=578$ when incomplete data excluded)

\begin{tabular}{lrrrr}
\hline & Hemoccult & HO Sensa & Hemeselect & Two-tier \\
\hline Cost of tests & $\$ 1,734$ & $\$ 2,023$ & $\$ 12,138$ & $\$ 3,640$ \\
Colonoscopy for D, H, F & $\$ 4,800$ & $\$ 6,300$ & $\$ 1,500$ & $\$ 300$ \\
Colonoscopy complications & $\$ 270$ & $\$ 462$ & $\$ 84$ & $\$ 36$ \\
$\quad$ Colonoscopy for all other positives & $\$ 8,700$ & $\$ 16,800$ & $\$ 2,700$ & $\$ 1,500$ \\
Totals & $\$ 15,504$ & $\$ 25,585$ & $\$ 16,422$ & $\$ 5,476$ \\
Cost per cancer detected & $\mathrm{NA}$ & $\$ 25,585$ & $\$ 16,422$ & $\$ 5,476$ \\
\hline
\end{tabular}

All costs are expressed in Canadian dollars. D Diverticulitis; F Fissures; H Hemorrhoids; NA Not applicable. Hemoccult $=\$ 3 / 3$ tests; HO Sensa $=\$ 3.50 / 3$ tests; Hemeselect $=\$ 21 / 3$ tests; Twotier $=\$ 3.50 / 3$ HO Sensatests $(+\$ 21$ for Hemeselect tests in the case of postive HO Sensa): Colonoscopy $=\$ 300$; Perforation $=\$ 6,000$; Rate of perforation $=1 / 1000$

subgroup ( $n=678$ ) of the second arm in the study produced similar results. At the level of test costs no clear-cut cost advantage is observed, except that Hemeselect as a first screen seems excessively expensive. Hemoccult is lowest at $\$ 1,734$ and Hemeselect is highest at $\$ 12,138$. The two-tier test costs reflect the complete HO Sensa test cost plus Hemeselect test costs related to positive HO Sensa results. However, once diverticular disease, hemorrhoids and fissures are figured into an economic equation (assuming follow-up colonoscopy), the two-tier test reveals distinct cost advantages. The figure of $\$ 3,940$ (tests and colonoscopy for false positives) for the two-tier test compares very favourably with the $\$ 6,534$ cost of the Hemoccult test. Add the cost of complications and colonoscopy for other positives and the economic benefit grows. At this stage the total costs for screening are $\$ 15,504$ for Hemoccult, $\$ 25,585$ for HO Sensa, $\$ 16,422$ for Hemeselect and $\$ 5,476$ for the two-tier test (Table 6). Because one cancer was found in this group, these figures also represent the cost per detected cancer (except for Hemoccult which did not pick up the one cancer).

Because the second of two tiers in the two-tier test 'missed' one cancer possible legal considerations are in order. We suggest using the term 'reactive' instead of 'positive' first tier to hamper certain litigation strategies aimed at discrepancies between these two tiers.

We also argue that two combined tests will inevitably be less sensitive than the most sensitive tier simply because of chance. The more sensitive test (first test or 'reactive' test) includes the true positives; those who have polyps or cancers that bleed during the passage of tested stool and a relatively large number of patients who test 'reactive' due to other factors (eg, diet). This second group of false positives will inevitably include occasional cancers or polyps that didn't happen to be bleeding at the time. This gives the apparent anomaly of a 'more sensitive test'. A reductio ad absurdum would be a test with $100 \%$ positivity (bleeding or not) and that would have a perfect record. Perhaps a compromise is yearly testing which would give an improvement in the yield of positives. Clearly, stool occult blood testing is dependent on bleeding during the passage of stool tested. It is our belief that this can be as high as $90 \%$ with such specimens and that the two-tier test, as a result, proves a useful test for CRC. We therefore believe that a clear explanation of the tests avoids the problem of a patient believing that a negative test means no cancer.

In addition to apparent 'missed' cancers and possible litigation issues, the cost of detecting adenomatous polyps represents a second concern. In the asymptomatic category of the second arm of the study, two adenomatous polyps were detected by all tests except HO Sensa, which also identified one additional smaller polyp. In the entire second arm of the study the two-tier detected the fewest polyps. However, its ability to identify the same number 
of larger polyps as other tests must be noted. Clearly, this issue is most dependent on personal philosophies concerning the importance of detection and removal of polyps. We regard the detection of polyps less than $1.0 \mathrm{~cm}$ by the FOBT as minor in value and unnecessary to remove in the context of a population receiving annual FOBTs.

\section{CONCLUSIONS}

We offer the two-tier test as a more cost-effective FOBT due to a reduction of false positives. Potential 'missed' cancers, litigation issues and ability to detect polyps represent possible

\section{REFERENCES}

1. Canadian Cancer Statistics 1992.

Toronto: National Cancer Institute of Canada, 1992.

2. Eddy DM. Screening for colorectal cancer. Ann Intern Med 1990;113:373-84.

3. Mandel JS, Bond JH, Church TH, et al. Reducing mortality from colorectal cancer by screening for fecal occult blood. N Engl J Med 1993;328:1365-71.

4. Cleator IGM. Strategies for application of fecal occult blood tests to screening. Proceedings of a satellite meeting of the World Congress of Gastroenterology, August 1990, Sydney, Australia. difficulties with this FOBT. Additionally, numbers in our study are relatively small and will require validation of these trends in future investigations. Kaiser Permanente (California) is conducting a much larger evaluation of the two-tier test and initial results from a screen of over 8000 patients are promising. Allison and colleagues (12) suggest that the two-tier actually detects more CRCs than Hemoccult II while limiting the number of follow-up investigations compared with HO Sensa.

Despite the limitations mentioned, we argue that fewer false positives and

5. Eddy DM. Screening for colorectal cancer in a high-risk population. Gastroenterology 1987;92:682-92.

6. Eddy DM. Screening for colorectal cancer. Ann Intern Med 1990;113:373-84.

7. Walker A, Whynes D. Filtering strategies in mass population screening for colorectal cancer. Med Decis Making 1992;12:2-7.

8. Trehu E, Cooper J. Cost of screening for colorectal cancer. South Med J 1992;85:248-54.

9. US Congress, Office of Technology Assessment. Costs and effectiveness of colorectal cancer screening in the elderly - Background paper. thus fewer resultant diagnostic workups place the two-tier test in the position of most cost-effective FOBT among those offered today.

ACKNOWLEDGEMENTS: We thank SmithKline Diagnostics and private donations to the GI Research Fund for sponsoring this study and the following participants: Ronald Feldman MD, Escondido, California; Jerald Fingerut MD, Norristown, Pennsylvania; Drs A Schoengold, R Merino, A Conrad, D Rouseau and R Gilroy, Poway, California; W Steinberg MD, George Washington University, Washington DC; and G Wallis MD, Naples, Florida.

Washington: US Government Printing Office, 1990.

10. Byers T, Gorsky R. Estimates of costs and effects of screening for colorectal cancer in the United States. Cancer 1992;70:1288-95.

11. Goosenberg EB. Fecal occult blood tests: A comparison. Contemp Gastroenterol 1992;Nov/Dec:6-9.

12. Allison JE, Tekawa I, Ranson L, Adrian A. Combination fecal occult blood test (Hemoccult II ${ }^{\circledR}$, Sena ${ }^{\circledR}$, Hemeselect $(\circledR)$ : A promising alternative to Hemoccult II for detection of CR neoplasms in mass screening of average risk patients. Gastroenterology 1992;102 (4 Pt 2):A340. 


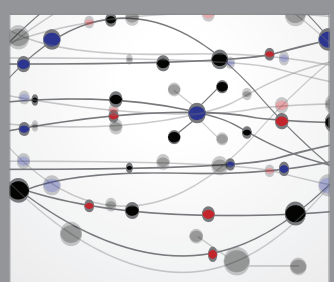

The Scientific World Journal
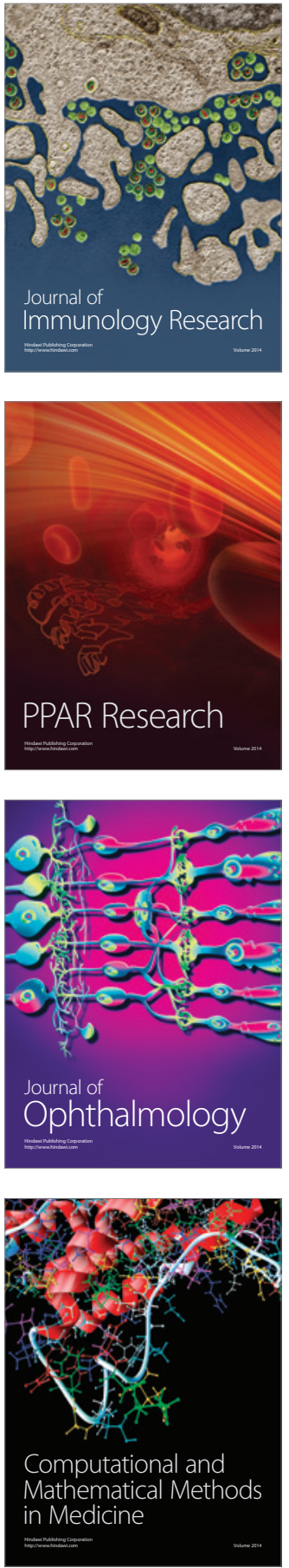

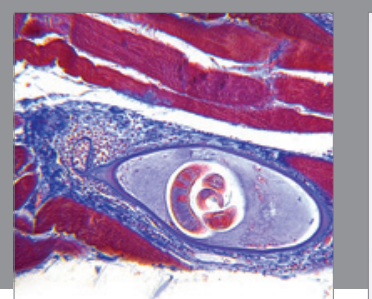

Gastroenterology Research and Practice

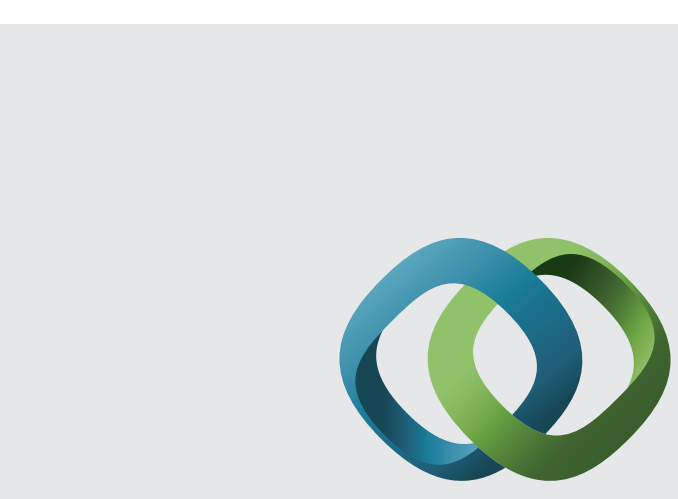

\section{Hindawi}

Submit your manuscripts at

http://www.hindawi.com
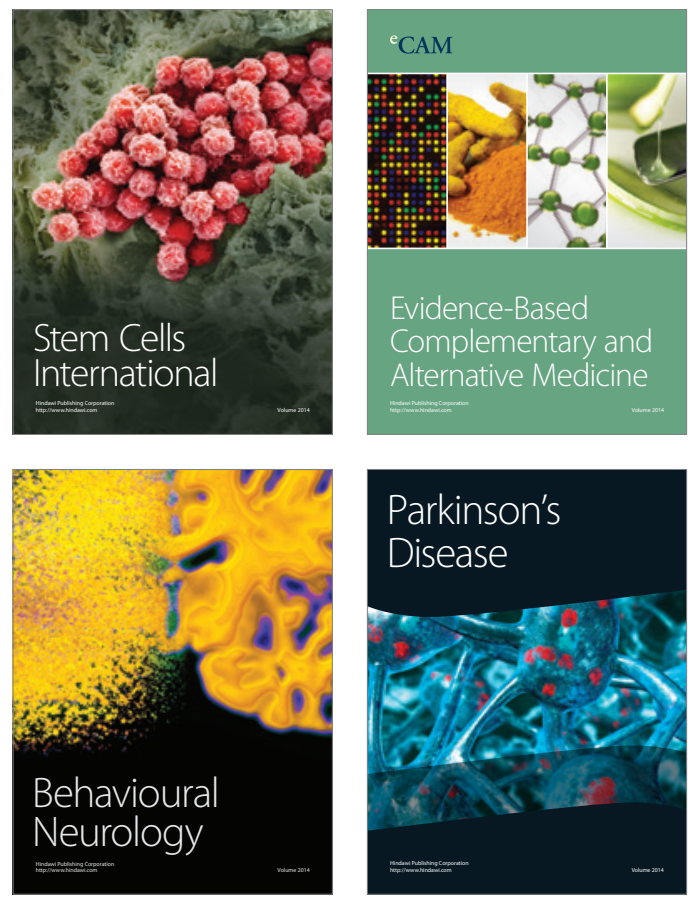
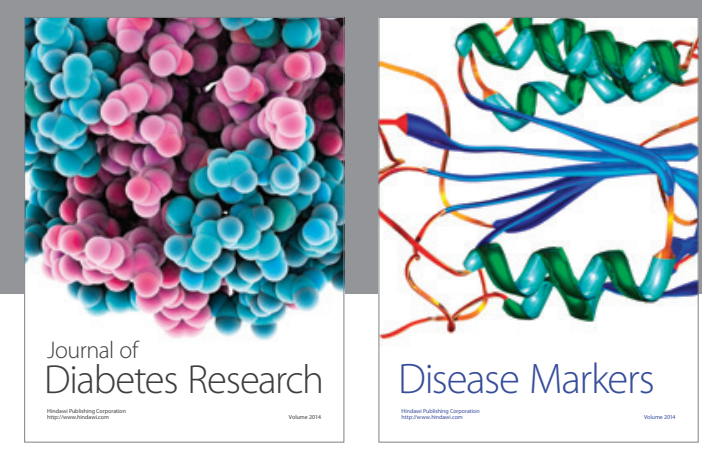

Disease Markers
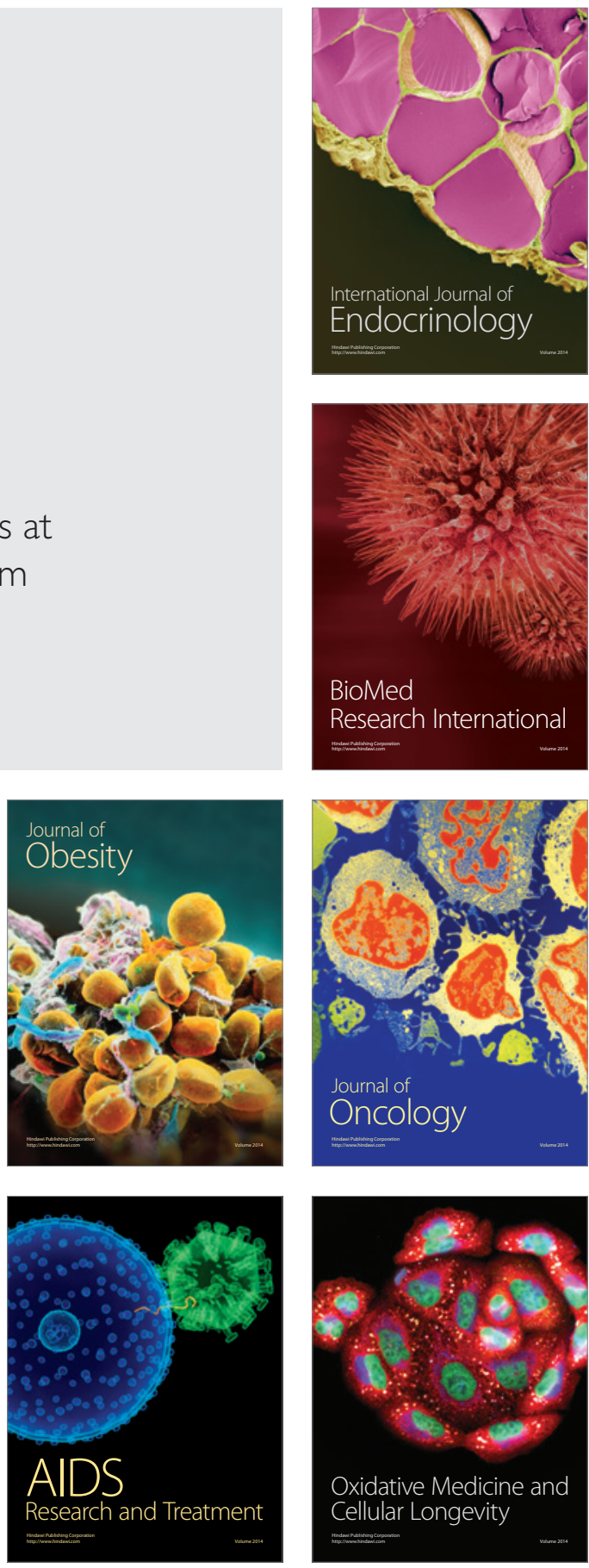